\title{
HIGHER EDUCATION INSTITUTIONS' NEED TO INITIATE CHANGE TO THE ACCOUNTING CURRICULUM DURING THE FOURTH INDUSTRIAL REVOLUTION (4IR)
}

\author{
Shaun Peens \\ Department of Languages and Social Sciences, Central University of Technology, \\ Free State (South Africa)
}

\begin{abstract}
In South Africa, the Further Education and Training phase (FET) in Accounting faces a major decline in learner numbers. The current format of FET Accounting serves little purpose in preparing learners for Accounting courses at tertiary level, if FET Accounting is not a precondition to Professional and Chartered Accountant courses. This study followed a qualitative research approach, from five Focus Groups at five Secondary schools in the Motheo Educational district, comprising of 16 FET Accounting Teachers to consider possible reasons for the decline of learners in FET Accounting. As result, uncertainty exists regarding the future of FET Accounting and the Accounting profession, when guidance teachers are presumably advising learners to take less suitable subjects, like Mathematical Literacy, History of Geography to enhance school reports. These findings influence the social responsibility of teachers; and it also results in many Accounting students having to spend two or more additional years at university due to their apparent lack of basic Accounting skills. Additionally, the negative perception towards FET Accounting might impact learners' choices who might not plan a career in Accounting, thereby limiting their ability to secure any career in the financial sector. Collaborative social change is required from the Accounting profession and university alike, especially in the Fourth Industrial Revolution era, where a high degree of ethics and transparency are required.
\end{abstract}

Keywords: Higher education, accounting, further education and training, 4IR.

\section{Introduction}

Did the Fourth Industrial Revolution (4IR) influence (or satisfy) our needs before we realising its existence? How are the Accounting profession and specifically University lecturers going to respond to it? More importantly, when?

In the South African context, Accounting is offered in Grades 10 to 12 (learners aged between 15 and 18); commonly referred to the Further Education and Training (FET) phase. Prior to the FET phase learners in the Senior Phase (SP) are exposed a subject named Economic and Management Sciences (EMS) where Accounting, Business Management and Economics are tangled as one subject, which is compulsory to all SP (Grades 7, 8 and 9) learners (SA Study, 2018).

Investigation at high schools in the Motheo district (Central parts of South Africa), indicated a major decline in learner numbers for FET Accounting linked to selective and/or insufficient assistance from guidance teachers. Additionally, inconsistent pre-requirements from university programmes in Accounting, impacted whether FET Accounting in its current format (curriculum) still serves a contributing resolve to prepare learners for Accounting courses at University and ultimately for the work force.

As an academic the feedback from FET Accounting learners mentioning Accounting as not interesting tend to initiate reflective measures on personal and future choices. It inflates pondering time of value and purpose of Accounting.

Olsen (2011) in Fin24 magazine addresses the discourse in FET Accounting at school level by suggesting possible ways and means to ensure and safeguard the preservation of Accounting as a subject. With 4IR looming around every corner and realising the impact it made during the past 12 months with the COVID pandemic it widened the debate whether the Accounting profession and University lecturers would respond in time to the Fourth Industrial Revolution (4IR) impact on education? 


\section{Purpose of this article}

The main purpose employed in this study was to measure the enthusiasm and opinion Accounting Teachers have with regards to teaching FET Accounting; their willingness to keep on teaching Accounting whilst challenging the importance and validity of the FET Accounting curriculum in its current form compared to challenges posed by the 4IR. The researcher is concerned whether FET Accounting remains relevant to the needs of Accounting Education Departments at universities and the industry itself.

An unprecedented objective emerged where the researcher attempted to determine if FET Accounting and Accounting Education in general are on track compared to the current 4IR influences on the Accounting industry. Klaus Schwab; who coined the 4IR term; stated: "4IR is evolving at an exponential rather than linear pace, disrupting almost every industry in every country". Therefore, the researcher is of the opinion that failing to keep up with current changes in the industry, the education sector, ultimately Accounting Education, will ultimately be left behind. The researcher argues that it is our social responsibility to bring about changes in schools so that our learners will survive and flourish in the 4IR.

\section{Methodology}

Lecturing FET Accounting Methodology and previous exposure to the practice of Accounting, the researcher opted to follow a qualitative approach, specifically employing a phenomenological research method. According to English and English (in Cohen, Manion and Morrison, 2011) phenomenology is a theoretical point of view that advocates for the direct experience taken at face value and an orientation which views behaviour as determined by the phenomena of experience instead of an external, objective and physically described reality. With this method the researcher gathered accurate information and perspectives from FET Accounting Teachers and their Head of Departments (HOD's) in FET Accounting at selected high schools in the Motheo Education District. Schools were purposefully selected to represent different schooling backgrounds; including, Afrikaans, English and Sesotho as language medium; Urban, Suburban and rural as well as wealthy versus poor school. Respondents were as a matter not chosen in the same measure as schools were, but rather a result of being the FET Accounting teacher at the particular schools, with the number of teachers varying per school. These focus group interviews were done after normal working hours with limited influence on their teaching schedule, were voluntary and responses were recorded audibly and transcribed, while the researcher took individual notes to clarify possible uncertainties with follow up conversation and questions.

\section{Focus group interviews}

The researcher agrees with James, Milenkiewicz and Bucknam (2008) and Tomal (2003) that a focus group is a distinctive brand of group interview, generally consists of about five to ten people, who are interviewed in a comfortable, non-threatening setting. De Vos in De Vos, Delport, Fouché and Strydom (2005) in turn explains it as planned discussions aimed at a distinct audience, with the purpose of promoting self-disclosure among participants. An aim of focus groups is to gain a broad range of views on the research topic over a period of 60-90 minutes by creating an environment where participants feel comfortable to express their views as mentioned by Hennink, Hutter and Bailey (2011). As a norm the environment should be non-threatening to all focus group members, preferably a known area.

Data gathering concluded from Focus Group interviews at five selected schools in the Motheo Education District, comprising of a total of 16 FET Accounting Teachers. From the five schools; four indicated Social change is important, all five suggested 4IR will have a huge impact on their method and ability of teaching, and only one school suggested that they will embrace the possible change.

\section{Ethical considerations}

Ethics, defined by Neuman (2006) as what 'is' or 'is not' legitimate to do, or what moral research procedure it involves agrees with the researcher's point of view that ethical issues involve a balance between the pursuit of the rights of those being studied and scientific knowledge. Written consent was therefore obtained from the Department of Basic Education, selected schools and the Central University of Technology. The researcher made a written request to the Principals and the school governing bodies to avail the FET Accounting Teachers to obtain their opinions and working papers, as this data was used to form the background information for the researcher.

\section{Limitations}

This study resorts under the teaching and learning of Accounting Teachers in the Further Education and Training phase (FET) in the Motheo Education District. The researcher followed the outlines as mentioned by Rule and John (2011), as well as Babbie and Mouton (2007) considering both advantages and disadvantages this study could afford. The following limitations were identified: 
1. In all cases, time was of the essence and the conversations seemed rushed. Some participants were too eager to respond to the questions, limiting the responses from other participants, resulting in loss of interest. It seemed difficult for some participants to adhere to the scheduled time frame due to circumstances beyond their control.

2. Focus groups are useful for gaining a sense of the range and diversity of views; whose views are dominant and/or marginal within the group as well how dialogue shifts the understanding of the group members, but unfortunately, the group environment lacks confidentiality, which indicates that focus group discussions could not be ideal for seeking the personal experiences of participants.

3. During the focus groups it was evident that participants felt that being too honest might expose their ability to teach, especially for school with only 2 respondents.

\section{Results}

Results from the study includes a discussion on (1) the value FET Accounting contributes to teaching and learning in Accounting courses at Higher Education Institutions; followed by an elaboration on (2) Focus Group feedback and declining numbers compared to research done by Kohler (2012) and (4) the impact 4IR may have on the Accounting Sector with consequential changes to the FET Accounting curriculum.

\subsection{Value of FET accounting}

Without a doubt the researcher concurs with research outcomes from Rankin, Silvester, Vallely and Wyatt (2003) as well as Barnes, Dzansi, Wilkinson and Viljoen (2009) who asserted that secondary school (FET) Accounting is beneficial to the performance of students in their first year of Accounting studies if there is a close association between the two curricula. The researcher agrees with Rankin et al. (2003) that topics in the school curriculum including The King Code III on corporate governance, Managerial Accounting, Audit-sampling techniques and the use of information technology assists students in their first-year of university Accounting. Although it could be argued these topics were added to the school curriculum only recently, all students who had matriculated since 2008 should have been exposed to these topics when they reach university.

From the Focus Groups, respondents seems to agree that the FET Accounting curriculum has an impact on learners (later students') understanding of basic Accounting concepts and builds a strong foundation for First Year Students to cope with university Accounting curricula and assessment. Without the constructive building of Accounting, basic principles as mentioned by Rankin et al. (2003), students at university level are at the losing end during their tertiary studies; possibly forced to extending their studies or terminating it. The researcher found it out of the ordinary that a learner with the intention to continue his/ her tertiary studies in Accounting would not choose FET Accounting at school as it serves to enhance their basic understanding of the field.

\subsection{Focus group feedback and declining numbers - Study}

Although some teachers suggested they would rather withheld their opinion avoiding exposure as the weak link in the chain, it later became clear they are not part of the subject guiding process. Respondents were asked what might led to the decrease in FET Accounting number at secondary schools. Most noteworthy suggested that FET Accounting might be perceived as a difficult subject. In line with coding explained in the Methodology section, the following comment were significant:

FGA1: "Declining numbers is a concern; it might be that FET Accounting is perceived to be more difficult than it used to be and therefore the learners do not want to take anymore."

Table 1. NSC enrolment in Accounting and Mathematics (Accounting extracted) ${ }^{l}$.

\begin{tabular}{|l|r|r|r|r|r|}
\hline & 2015 & 2016 & 2017 & 2018 & 2019 \\
\hline Accounting & 140474 & 128853 & 103427 & 90278 & 80110 \\
\hline
\end{tabular}

Table 1 indicates how the numbers, combined from DoBE (2019) of learners writing FET Accounting during the National Senior Certificate declined from 2015 to 2019. Reiterating the feedback, the Focus Groups mentioned that one possible reason why numbers are declining might be due to suggestions from Guidance Teachers demotivating learner to choose FET Accounting and promoting Mathematics as a requirement for Chartered Accountant (CTA) courses at major universities. Having mentioned these possibilities the researcher expected the number in Mathematics students to increase as FET Accounting number decrease; but that does not seem to be the case as derived from table 2.

${ }^{1}$ Source: National Senior Certificate Diagnostic Report Part 1 - 2019 (21 April 2021)

https://dbedashboard.co.za/School-Improvement/wp-content/uploads/2020/07/Accounting-2019.pdf 


\subsection{Impact of the fourth industrial revolution}

The Accounting Industry has undergone major reformation since the 1990's as stated by SAICA in the CA2025 drive (BizCommunity, 2018). SAICA mentioned that the Charted Accountant Industry future seems not too dependent on how well Accountants do calculations, but rather on how well they understand the development in the Industry and understanding what certain calculations and disclosures deem to inform the users of financial information. At the inception of this study the researcher felt that FET Accounting should focus primarily on building a strong Accounting foundation by emphasising the basic principles, rather than teaching complicated concepts not directly related to Financial Accounting and bound to change when new technologies will impact on their tertiary studies. A sustainable learning environment is determined by the eagerness of FET Accounting Teachers and learners to accept social change and acceptance that the technological advancements the world is experiencing will only be enhanced and become more complex.

An article in 'See the Future' published in CarringtonCrisp (2014) pointed out that since the 1980 's, research into higher education has explored the digital shift taking place in universities. In South Africa this shift towards technology seems to be more challenging as one of the greatest obstacles in Higher Education Institutions in the 21 st century is not the new technologies themselves, but the ability of educators to embrace the changes brought about by educational technologies. One aspect the researcher observed during visits to schools is the lack of computerized equipment. The reason this serves as a problem is that schools will not be able to match the fast-growing pace of technology Ernst and Young (2013) expects in the private sector. Tynan, Ryan, Hinton, and Lamont Mills (2012) and NMC (2014) point that the challenge existed since the research in 1994, and for this reason, the Accounting profession must push schools and tertiary institutions to adapt and keep up with the fast-paced financial sector fit for its survival.

The Adaptation of technology in Africa, and indeed in South Africa as well has shown a slow adaptation rate since the 1990's, which strengthens the view of Africa as dark, as some countries are struggling to keep the lights on. Although South Africa's private sector is all but behind, it has to be admitted that government schools indeed are feeding off the scraps. An accurate statement by Blair (2019) is "The Fourth Industrial Revolution (4IR) is upending the nature of work as we know it. Policymakers are struggling to grapple with this future in the West, but for African countries; and developing countries generally; the outlook appears even bleaker".

This notion from the Tony Blair Institute for Global Change, which indicates that South Africa, as a low-income country will generally take longer to adapt to new technology. It has to be confirmed that rapid adoption will be 1.2 times quicker than normal adoption for both high- and low-income countries. The reality however is that even a slow adoption in a high-income country seems to quicker and more beneficial than a rapid adoption in low-income country. The researcher realises that changing the country to rapid adoption seems more feasible and possible with accurate support and willingness compared to converting South Africa to a high-income country.

\section{Conclusion}

The researcher has not ventured into the reason why FET Accounting has been excluded as a pre-requirement for Accounting courses at selected universities, and even less understandable whom initiated the change in requirements between traditional universities and professional Accounting bodies. Maybe it is not by accident, and that possible gaps in FET Accounting existed for a while, and it was an easier step to exclude it, than to overhaul it. One argument the researcher can't put aside is that Mathematics drives creative and abstract thinking, and therefore might seem to be a valid alternative as pre-requisite.

A certain conclusion to be made is that industries should have a direct influence on the training learners and students receive, even though FET Accounting Teachers does not seem to be ready for the transition. With the fast pace of technological development and pressures from the corporate world, school and tertiary institutions cannot teach learners and students the basics and expect in service training to prepare them for the 'real job'. Training should be on point and directly related to the industry in which the individual wants to work. Universities, and Accounting lecturers in particular should have a clear vision to guide FET Accounting curriculum and drive the Accounting profession and not vice versa. This might suggest that the Teacher Education should adapt as well to ensure a new generation of FET Accounting Teachers enters the work force with the ability to embrace the much-needed changes.

Sustainable learning environments in schools, keeping the FET Accounting curriculum up to date, ensuring our learners can work around the globe with or without future intended Accounting studies. Guidance teachers should be assisted by universities in their guidance to learners' subject and career choices. The researcher believes that that keeping on drawing lines and casting totals seems outdated and if resources allow, learners should practise Accounting on Accounting Software. The world has entered an automated era where transactions are generated by technology, and the need to interpret them seems more important. If a learner can learn how to utilise Accounting software at secondary school, the industry will probably grab them with open arms. 


\section{Recommendation}

The researcher wants to emphasise that collaborative social change and responsibility rests on the shoulders of Accounting lecturers and the industry to voice the impact 4IR has on the workforce where a high degree of ethics and transparency is required, especially the availability of work in specific spheres. If Accounting as profession wishes to remain relevant, the method and content being taught at school, (and university level) should change to be on par and sustainable with the exponential growth of the 4IR.

\section{References}

Babbie, E. and Mouton, J. 2007. The practice of social research. Cape Town: Oxford University Press.

Barnes, H., Dzansi, D., Wilkinson, A. and Viljoen, M. 2009. Researching the first year accounting problem: Factors influencing success or failure at a South African higher education institution. Journal of New Generation Sciences, 7(2): 36-58.

Blair, T. 2019. Adapting to the 4IR: Africa's development in the age of automation. Available https://institute.global/insight/governance/adapting-4ir-africas-development-age-automation on July 4, 2019 [Accessed 12 September 2019]

Chartered accountants and 4IR https://www.bizcommunity.com/Article/196/511/182058.html on 19 September 2018. [Accessed 13 September 2019].

Cohen, L., Manion, L. and Morrison, K. 2011. Research methods in education. ( $7^{\text {th }}$ Edition). New York: Routledge.

De Vos, A. Delport. C., Fouché, B. and Strydom, H. 2005. Research at grass roots: For the social sciences and human service professions. ( $3^{\text {rd }}$ Edition). Pretoria: Van Schaik Publishers.

Ernst and Young. 2013. University of the Future: A thousand year old industry on the cusp of profound change. Available from http://hdl.voced.edu.au/1 0707/228059. [Accessed 8 March 2017].

Hennink, M., Hutter, M. and Bailey, I.A. 2011. Qualitative research methods. Los Angeles: Sage.

Hesse-Biber, S.N. and Leavy, P. 2011. The practice of qualitative research. (2nd Edition). Thousand Oaks: Sage.

James, E.A., Milenkiewicz, M. and Buckman, A. 2008. Participatory action research for educational leadership: Using data-driven decision making to improve schools. Los Angeles: Sage.

Kohler, S. 2012. SA basic education brief. Creamer Media's Mining Weekly, 1: 4.

Neuman, W.L. 2006. Social research methods: Qualitative and quantitative approaches. (6 ${ }^{\text {th }}$ Edition). Boston: Pearson Education.

NMC. 2014. NMC horizon report: 2014 Higher education edition. The New Media Consortium, Austin: Texas.

Olsen, S. 2011. Maths decline a threat to accounting. Fin24.com, February 1, 2011 Available from https://www.fin24.com/Nuus/Maths-decline-a-threat-to-accounting-20110201 on 2011-02-01. [Accessed 14 March 2018].

Rankin, M., Silvester, M., Vallely, M. and Wyatt, A. 2003. An analysis of the implications of diversity for students' first-level accounting performance. Accounting and Finance, 43:365-393.

Rule, P. and John, V. 2011. Your guide to case study research. Pretoria: Van Schaik.

SA Study. [n.d.]. Going to grade 10 next year? Available from http://sastudy.co.za/article/going-to-grade10-next-year/. [Accessed 14 March 2018].

Schwab, K.M. 2016. The Fourth Industrial Revolution: what it means, how to respond. World Economic Forum Agenda. [Web:] http://www.weforum.org/agenda/2016/01/the-fourth-industrial-revolutionwhat-itmeans-and-how-to-respond. [Access 19 September 2019].

See the future. 2014. Carrington Crisp, ACCA, EFMD. http://www.carringtoncrisp.com/images/ PDFs/See_The_Future_2014.pdf. [Accessed 12 April 2016].

South Africa's Education statistics. South African Market Insights. 2019. https://www.southafricanmi.com/education-statistics.html last updated 29 May 2019. [Accessed 13 September 2019].

Tomal, D.R. 2003. Action research for educators. Lanham, Md.: Scarecrow Press.

Tynan, B., Ryan, Y., Hinton, L. and Lamont Mills, A. 2012. Out of hours: Final report of the project e-teaching leadership: Planning and implementing a benefits-oriented costs model for technology enhanced learning. Sydney: Australian Learning and Teaching Council (ALTC). 